\title{
Precipitation Behavior and Magnetic Properties of Cu-Fe-Co Alloys Containing Nanogranular Ferromagnetic-Element Particles
}

\author{
N. Wada, ${ }^{1}$ K. Kuwada, ${ }^{1}$ J. S. Kim, ${ }^{1}$ M. Takeguchi, ${ }^{2}$ and M. Takeda ${ }^{1}$ \\ ${ }^{1}$ Department of Materials Engineering (SEISAN), Yokohama National University, 79-5 Tokiwadai, Hodogayaku, \\ Yokohama 240-8501, Japan \\ ${ }^{2}$ Advanced Electron Microscopy Group, National Institute of Materials, Sakura 3-13-3, Tsukuba 305-0003, Japan
}

Correspondence should be addressed to M. Takeda; mtakeda@ynu.ac.jp

Received 31 March 2015; Accepted 28 September 2015

Academic Editor: Victor V. Moshchalkov

Copyright (C) 2015 N. Wada et al. This is an open access article distributed under the Creative Commons Attribution License, which permits unrestricted use, distribution, and reproduction in any medium, provided the original work is properly cited.

\begin{abstract}
This work investigates the evolution of microstructures and magnetic properties during isothermal annealing of $\mathrm{Cu}-\mathrm{Fe}-\mathrm{Co}$ alloys, using electron microscopy and superconducting quantum interference device (SQUID) magnetometry. Small coherent granular precipitates composed of iron and cobalt formed in the copper matrix in the early stage of precipitation. As annealing proceeded, the precipitates lost coherency to the matrix after reaching a size of $15-20 \mathrm{~nm}$ and twin-like structures were consecutively introduced in the particles. The SQUID measurements revealed that the magnetic properties of the specimens correlated with the microstructural evolution. The coercive force initially increased with annealing time but decreased after reaching a peak. Lorentz Microscopy suggested that the initial large increase of magnetization was invoked by a structural transition from fcc to B2 in the precipitates.
\end{abstract}

\section{Introduction}

Nanogranular ferromagnetic materials have been investigated extensively in recent years, not only from fundamental interest but also because of their high potential for applications in practical electric devices such as magnetoresistive random access memory (MRAM). After the discovery of the giant magnetoresistive (GMR) effect in multilayered conjunctions of nonmagnetic and magnetic elements $[1,2]$, Berkowitz and Xiao extended GMR studies to nanogranular magnetic materials and confirmed that metallic materials containing ultrafine granules of ferromagnetic atoms also exhibit the GMR effect $[3,4]$. Based on accumulated evidence from successive studies on GMR materials, it is now accepted that microstructural parameters including particle sizes, shapes and composition, interfacial roughness, and interparticle distances all influence the magnetic properties $[5,6]$. Nevertheless, systematic investigation on the detailed influences of microstructure on the magnetic properties of granular GMR materials still remains incomplete.
According to the $\mathrm{Cu}$-Fe phase diagram, Fe-rich precipitates form in a copper-based $\mathrm{Cu}-\mathrm{Fe}$ alloy and have a bodycentered cubic lattice (bcc) structure below a temperature of $1093 \mathrm{~K}$. However, small face-centered cubic (fcc) Fe precipitates have also been reported to be stable in the initial stage of precipitation: these particles are spherical and retain their coherency to the copper matrix. Takeda et al. [7-9], Rocha et al. [10], and Fujita et al. [11] have independently investigated the microstructural evolution of $\mathrm{Cu}-\mathrm{Co}$ alloys and they have confirmed that a linear alignment of cobalt precipitates forms in a copper matrix during isothermal annealing. As the precipitation processes in all these alloys proceed, ferromagnetic precipitates undergo structural and magnetic changes [12]. Similar works have also been carried out to investigate precipitation in immiscible ternary $\mathrm{Cu}-\mathrm{Fe}-$ Co $[13,14]$ and $\mathrm{Cu}-\mathrm{Fe}-\mathrm{Ni}$ alloys [15]. However, details of the relationship between microstructure and physical properties have not yet been fully clarified. In this context, nanoscale $\mathrm{Fe}$ Co particles in a ternary $\mathrm{Cu}-\mathrm{Fe}-\mathrm{Co}$ alloy are of considerable scientific interest, because such alloys exhibit high magnetic 


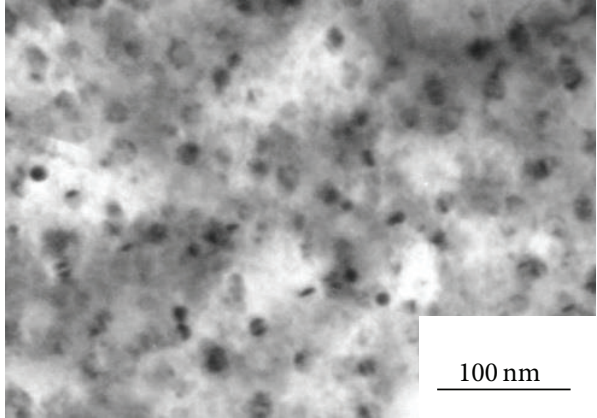

(a) $50 \mathrm{~min}$

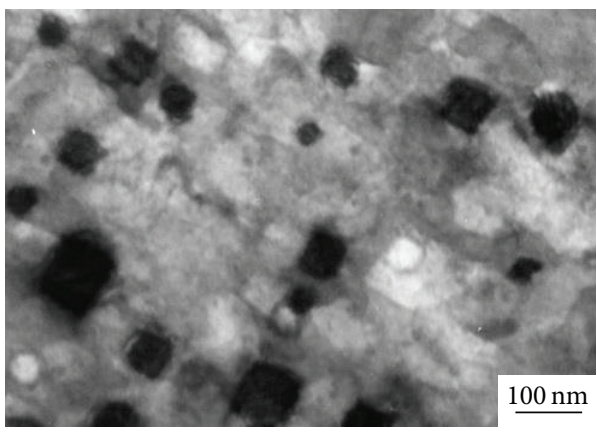

(c) $2000 \mathrm{~min}$

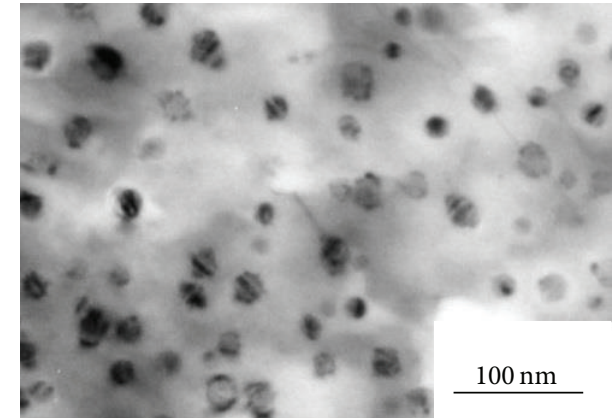

(b) $100 \mathrm{~min}$

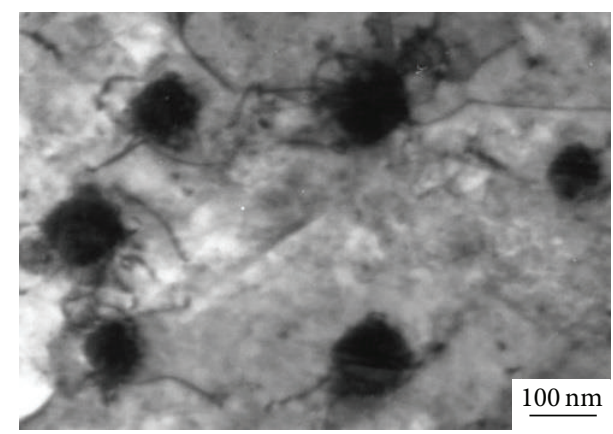

(d) $5000 \mathrm{~min}$

Figure 1: Bright field TEM images of Cu-1.8at\%Fe-1.2at\%Co annealed at $973 \mathrm{~K}$.

saturation. The present study aims to clarify the correlation between microstructural evolution and magnetic properties in $\mathrm{Cu}-\mathrm{Fe}-\mathrm{Co}$ alloys, using conventional and high-resolution electron microscopy, Lorentz microscopy, and SQUID measurements. To investigate the coalescence of iron and cobalt atoms, the element mapping technique based on energy-loss spectroscopy (EELS) was also implemented.

\section{Experimental}

The specimens of $\mathrm{Cu}-\mathrm{Fe}-\mathrm{Co}$ used in the present study were prepared by arc melting of pure source metals. They were homogenized by repeating melting, cold-rolling, and annealing just below the melting points. Discs $3 \mathrm{~mm}$ in diameter were punched from homogenized sheets $130 \mu \mathrm{m}$ thick. The disc specimens were sealed in evacuated silica tubes and solution-treated at $1273 \mathrm{~K}$ for $60 \mathrm{~min}$. After the solution treatment, all specimens were immediately quenched in ice water $(273 \mathrm{~K})$, and subsequently isothermal annealing was carried out using a furnace kept at 773,873 , or $973 \mathrm{~K}$ for various periods up to $10000 \mathrm{~min}$.

The specimens for TEM observations were prepared by jet electropolishing with a solution of $75 \%$ methanol and 25\% nitric acid. Bright-field TEM observations of alloy microstructures were made using a HITACHI H-800 transmission electron microscope. High resolution and EELS element mapping images were obtained, using a JEM-3010F field emission transmission electron microscope operated at $300 \mathrm{kV}$. Lorentz microscopy was carried out using a Topcon EM-002BL. We took all TEM, HRTEM, and EELS images from $\langle 001\rangle$ zones of the copper matrices. The magnetization measurements were performed using a Quantum Design MPMS SQUID magnetometer. Closed M-H hysteresis curves were acquired with the applied field in a range from -4 Tesla to +4 Tesla.

\section{Results and Discussion}

3.1. Bright Field TEM Observations. We first confirmed that no clearly visible precipitates were present in a specimen which had only been solution-treated. Then we investigated the microstructural evolution of precipitation in a $\mathrm{Cu}-\mathrm{Fe}-\mathrm{Co}$ alloy isothermally annealed at $973 \mathrm{~K}$. Figure 1 shows bright field TEM images of the $\mathrm{Cu}-1.8$ at $\% \mathrm{Fe}-1.2 \mathrm{at} \% \mathrm{Co}$ alloy aged for (a) $50 \mathrm{~min}$, (b) $100 \mathrm{~min}$, (c) $2000 \mathrm{~min}$, and (d) $5000 \mathrm{~min}$, respectively. At annealing times of 50 and 100 minutes, small granular precipitates of spherical appearance were visible throughout the copper-rich matrices and grew in size from $\sim 10$ to $\sim 30 \mathrm{~nm}$. Small precipitates of diameter less than $15 \mathrm{~nm}$ showing weak contrast in Figure 1(b) have round or slightly elongated shapes. These precipitates are likely to be fcc in structure and coherent with the copper matrix. We note however that many precipitates with larger sizes in Figure 1(b) show black and white striped contrast, which suggests the formation inside them of a twin-like structure. This and the relatively strong contrast of these larger precipitates suggest that they may already have transformed into incoherent precipitates. Incoherent precipitates of cubic shape and with accompanying interfacial dislocations were readily identifiable when the mean size of precipitates reached about $70 \mathrm{~nm}$ 


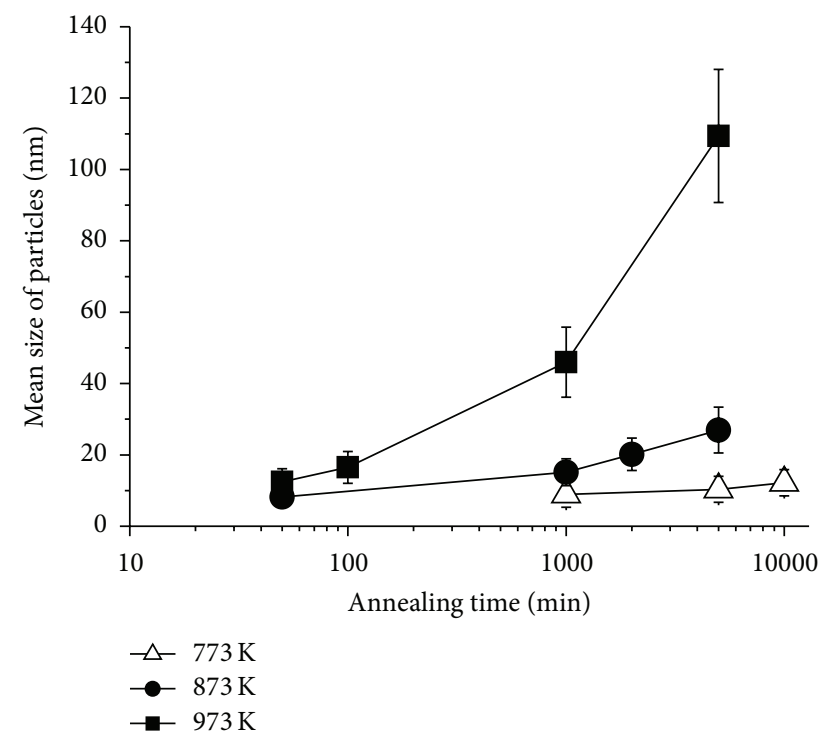

FIGURE 2: Mean size of precipitates of $\mathrm{Cu}-1.8 \mathrm{at} \% \mathrm{Fe}-1.2 \mathrm{at} \% \mathrm{Co}$ annealed at $773 \mathrm{~K}, 873 \mathrm{~K}$, and $973 \mathrm{~K}$.

(Figures 1(c) and 1(d)). At the earliest stage, there was some indication that precipitates formed in pairs. This seems to be similar to the trend for linear alignment of precipitates along $\langle 001\rangle$ matrix directions, which has been found previously in $\mathrm{Cu}-\mathrm{Co}$ alloys but occurs more weakly in $\mathrm{Cu}-\mathrm{Fe}$ alloys [79, 13-15].

We made similar TEM observations of specimens which had been isothermally aged at lower temperatures, $773 \mathrm{~K}$ and $872 \mathrm{~K}$, in order to investigate the dependence of growth rates on annealing temperature. Figure 2 shows the mean sizes of precipitates versus time for different annealing temperatures in the $\mathrm{Cu}-\mathrm{Fe}-\mathrm{Co}$ alloy. The growth rate increases with annealing temperature, consistent with previous observations in $\mathrm{Cu}$ $\mathrm{Co}$ and $\mathrm{Cu}-\mathrm{Fe}$ alloys [7-9, 13-15]. The growth rates of precipitates were approximately a factor of ten smaller at $773 \mathrm{~K}$ and three times smaller at $873 \mathrm{~K}$ than at $973 \mathrm{~K}$. Although the precipitation behavior in $\mathrm{Cu}-\mathrm{Fe}-\mathrm{Co}$ was basically similar to that seen in binary $\mathrm{Cu}-\mathrm{Co}$ and $\mathrm{Cu}-\mathrm{Fe}$ alloys, the absolute growth rate of precipitates was slower.

Previous studies have found that the growth rates of precipitates are different in $\mathrm{Cu}-\mathrm{Co}$ and $\mathrm{Cu}-\mathrm{Fe}[7,13,14]$. If the rates of diffusion of iron and cobalt atoms were different from each other in the present case, the microstructure and magnetic properties might be affected by changes in the composition of precipitates during annealing. We have investigated this using the element mapping technique based on electron energy loss spectroscopy (EELS). Figure 3 shows EELS elemental maps of copper, iron, and cobalt for specimens annealed at $973 \mathrm{~K}$ for (a) 10, (b) 100, and (c) 2000 minutes, respectively. Comparing the distributions of iron and cobalt atoms in Figures 3(a)-3(c), one can recognize that iron and cobalt atoms are localized to similar degrees. Spherical precipitates comprise both iron and cobalt atoms, and no significant changes in iron and cobalt concentrations can be discerned.

The structure of incoherent precipitates was investigated by HREM. Figure 4 shows a high-resolution image and corresponding Fast Fourier Transforms (FFT), and inverse Fourier Transforms (IFFT) of a cubic incoherent precipitate formed after annealing at $973 \mathrm{~K}$ for $2000 \mathrm{~min}$. Figures 4(a)4(d) correspond to the atomic structure inside the precipitate, while Figures $4(\mathrm{e})-4(\mathrm{~h})$ correspond to the copper matrix. The spots appearing in Figure 4(b) are due to the lattice fringes of the B2 structure of the ordered FeCo intermediate phase. Figures 4(c) and 4(d) show digitally refined high-resolution TEM images obtained from the IFFT procedure where a mask has been used to reduce random noise. Figure 4(d) shows that the spacing of main lattice fringes is $0.107 \mathrm{~nm}$, which corresponds to the $\{200\}$ planes of the B2 structure. The IFFT images shown in Figures 4(g) and 4(h) have a lattice spacing of $0.182 \mathrm{~nm}$, which agrees with that of the $\{200\}$ planes of the copper matrix.

3.2. Magnetization Measurements. The magnetic properties of $\mathrm{Cu}-\mathrm{Fe}-\mathrm{Co}$ alloys were determined by measurement of a closed $\mathrm{M}-\mathrm{H}$ hysteresis loop at each step of the annealing sequence, using a SQUID magnetometer with an applied field in the range of \pm 4 Tesla at $5 \mathrm{~K}$.

Figure 5 shows the hysteresis loops of $\mathrm{Cu}-1.8 \mathrm{at} \% \mathrm{Fe}-$ 1.2 at $\%$ Co specimens annealed at $973 \mathrm{~K}$ for $10,50,1000$, and $5000 \mathrm{~min}$. All specimens exhibited the saturated magnetization at a similar level. However, we found that the specimen which annealed for $50 \mathrm{~min}$ showed the largest coercivity and anisotropy. Figure 6 shows the changes in the coercivity during isothermal annealing of $\mathrm{Cu}-1.8 \mathrm{at} \% \mathrm{Fe}-1.2 \mathrm{at} \% \mathrm{Co}$, $\mathrm{Cu}-0.6$ at $\% \mathrm{Fe}-0.4 \mathrm{at} \% \mathrm{Co}$, and $\mathrm{Cu}-0.4 \mathrm{at} \% \mathrm{Fe}-0.6$ at $\% \mathrm{Co}$ alloys. Although there is some experimental spread, the ternary $\mathrm{Cu}-1.8$ at\%Fe-1.2at\%Co alloy clearly shows higher values of coercivity than $\mathrm{Cu}-0.4 \mathrm{at} \% \mathrm{Fe}-0.6 \mathrm{at} \% \mathrm{Co}$ and $\mathrm{Cu}-0.6$ at $\% \mathrm{Fe}-$ 0.4 at $\%$ Co alloys. We also noticed that the cobalt content is more effective to coercivity. Thus, the replacement with cobalt of a part of the iron content of precipitates has brought about a considerable increase in coercivity. The largest gain was achieved in the $\mathrm{Cu}-1.8 \mathrm{at} \% \mathrm{Fe}-1.2 \mathrm{at} \% \mathrm{Co}$, which has a composition close to the balance of the Fe-Co alloy with the highest susceptibility. This suggests an important contribution of the ordered FeCo B2 phase to the magnetic properties.

The coercivities of all specimens increased quickly to a peak in the early stage of annealing and then decreased monotonously with aging time. Shima and Takanashi have also reported a tendency for the coercivity of a nanoscale magnetic material to reach a maximum and then decrease with increasing particle size. They claimed that the maximum of the coercivity may be related to the cooperative rotation of magnetic moments [16]. Besides this possibility, previous work has also revealed that the fcc phases in binary $\mathrm{Cu}$ $\mathrm{Fe}$ and Fe-Co alloys exhibit paramagnetism. The very small coherent $\mathrm{Fe}-\mathrm{Co}$ precipitates formed initially are therefore likely to have low coercivity. Such particles transform into the ordered ferromagnetic B2 state on annealing, leading to the initial increase in coercivity. At this stage the B2 FeCo particles probably consist of a single magnetic domain. The subsequent decrease in coercivity on further annealing may be due to the transformation of the single magnetic domain structure into a multiple magnetic domain structure at the point of the maximum coercivity. 

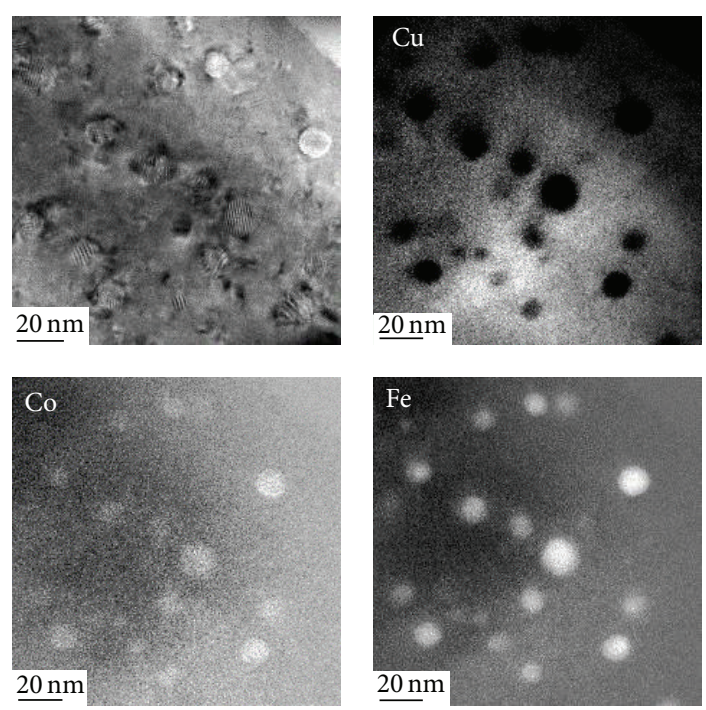

(a) 10 min TEM
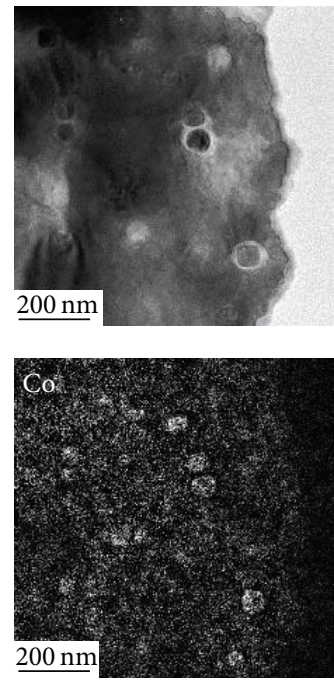
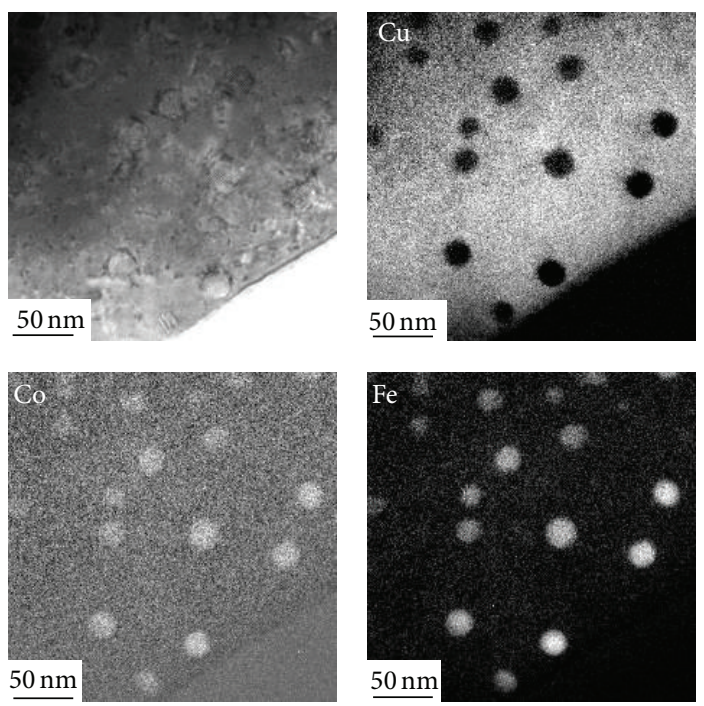

(b) 100 min TEM
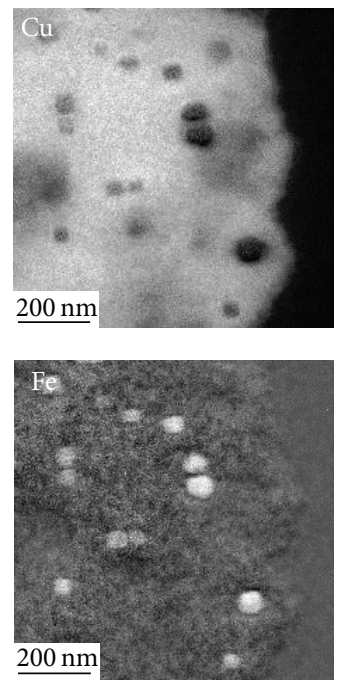

(c) $2000 \mathrm{~min} \mathrm{TEM}$

Figure 3: Elemental mapping images of precipitates with $\mathrm{Cu}, \mathrm{Fe}$, and $\mathrm{Co}$ EELS spectra in $\mathrm{Cu}-1.8 \mathrm{at} \% \mathrm{Fe}-1.2 \mathrm{at} \% \mathrm{Co}$ annealed at $973 \mathrm{~K}$.

3.3. Lorentz Microscopy. Lorentz microscope enables one to measure the magnitude and direction of the magnetization of small magnetic materials [17]. When the incident electron beam passes through a ferromagnetic material, the electrons are a subject to a Lorentz force due to the spontaneous magnetization of the material. In the low-angle diffraction (LAD) mode of Lorentz microscopy, we can detect the deflection of the electron trajectories as a parasitic spot (or a streak) of the Bragg reflection. In the present work, we examined the electron LAD patterns for six specimens. Each specimen contained $\mathrm{Fe}-\mathrm{Co}$ particles with mean sizes ranging from $\sim 10$ to $\sim 90 \mathrm{~nm}$. Figure 7 shows an example of electron diffraction spots obtained with the LAD mode. Parasitic spots were observed as streaks along $\langle 100\rangle$ directions due to the distribution of particle magnetization and sizes. This result indicates that Fe-Co particles are preferably magnetized along $\langle 100\rangle$ directions. We measured the distances between satellite spots and the fundamental Bragg reflections and estimated the magnitude of magnetic moments of Fe-Co particles. The change in electron momentum due to a magnetic field $B$ is given by

$$
m \Delta v=\operatorname{Bev} \Delta t=\operatorname{Bed}
$$

where $d$ is the deflection from the fundamental reflection, and the other symbols have their usual meaning. The deflection angle $\varphi$ is then

$$
\varphi=\frac{\Delta v}{v}=\frac{B e d}{m v}=\frac{B e d \lambda}{h}
$$

where $h$ is Planck's constant and $\lambda$ is the electron wavelength. 


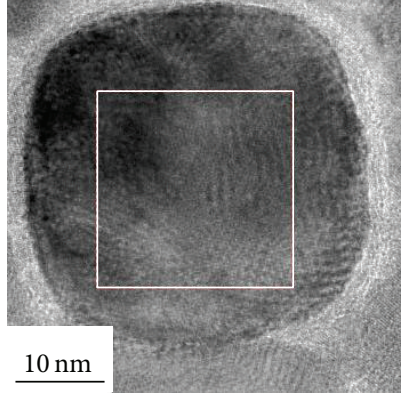

(a) HRTEM

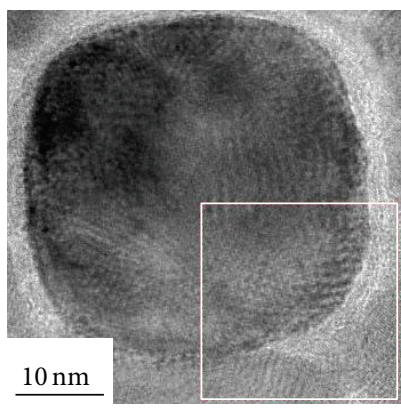

(e) HRTEM

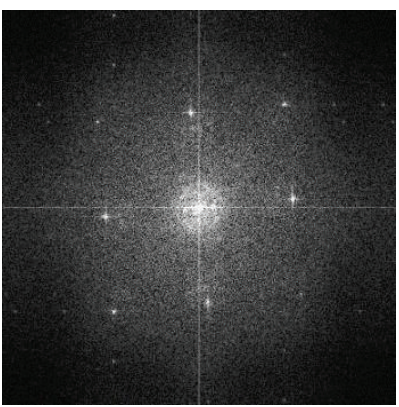

(b) FFT

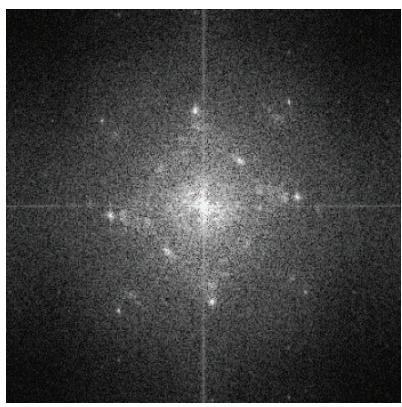

(f) FFT

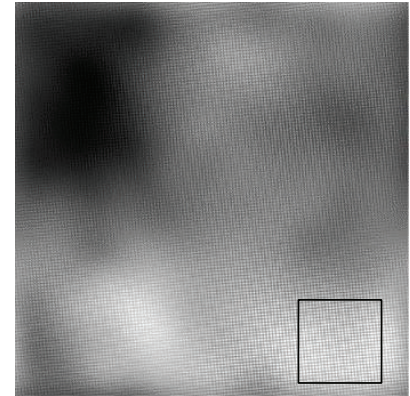

(c) IFFT

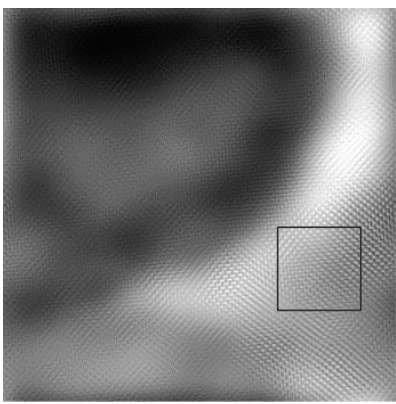

(g) IFFT

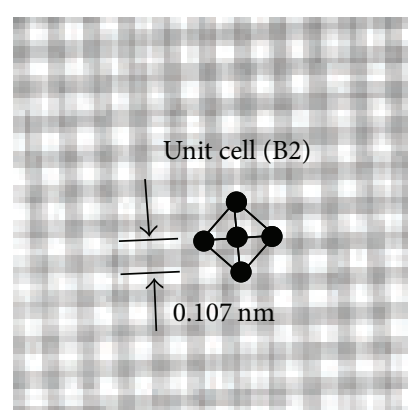

(d) Enlarged view

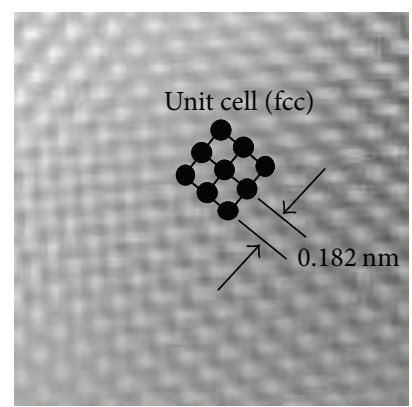

(h) Enlarged view

Figure 4: HRTEM, FFT, and IFFT images of Cu-1.8at\%Fe-1.2at\%Co.

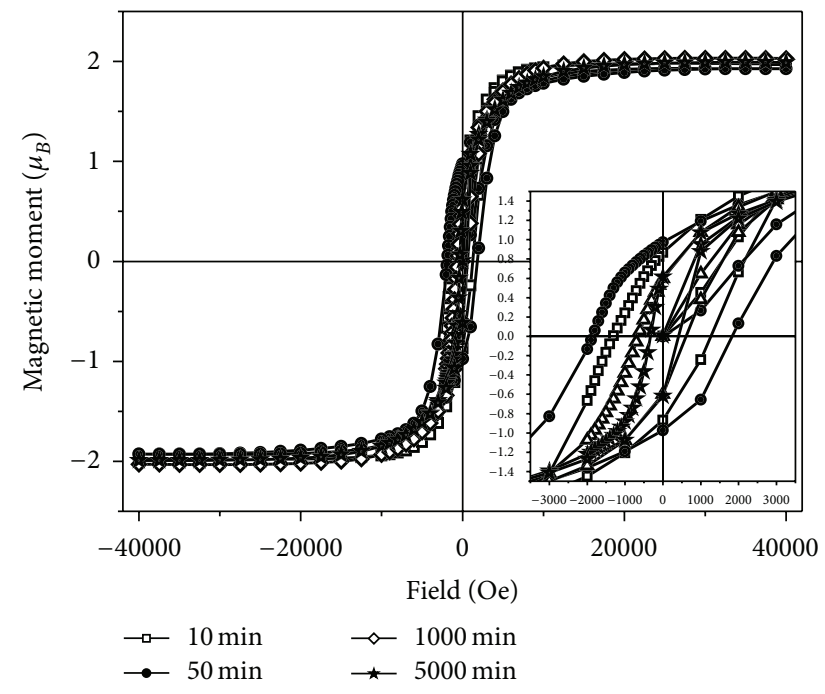

Figure 5: Hysteresis loops of $\mathrm{Cu}-1.8 \mathrm{at} \% \mathrm{Fe}-1.2 \mathrm{at} \% \mathrm{Co}$ samples annealed at $973 \mathrm{~K}$.

Figure 8 shows the relation between the deflection angle $\varphi$ and the mean size $d$ of particles obtained for $\mathrm{Cu}-1.8 \mathrm{at} \% \mathrm{Fe}-$ 1.2 at $\% \mathrm{Co}$ and $\mathrm{Cu}-3 \mathrm{at} \% \mathrm{Fe}$ alloys. The deflection angle was larger for the $\mathrm{Cu}-1.8 \mathrm{at} \% \mathrm{Fe}-1.2 \mathrm{at} \% \mathrm{Co}$ alloy than for the reference $\mathrm{Cu}-3 \mathrm{at} \% \mathrm{Fe}$ alloy, although for the smallest particles of mean size $\sim 8 \mathrm{~nm}$ the deflection angle was comparable and relatively low. The solid line in Figure 8 shows the calculated deflection angles for $\mathrm{Fe}-\mathrm{Co}$ particles with the B2 structure. Taking also the TEM and SQUID experiments into account,

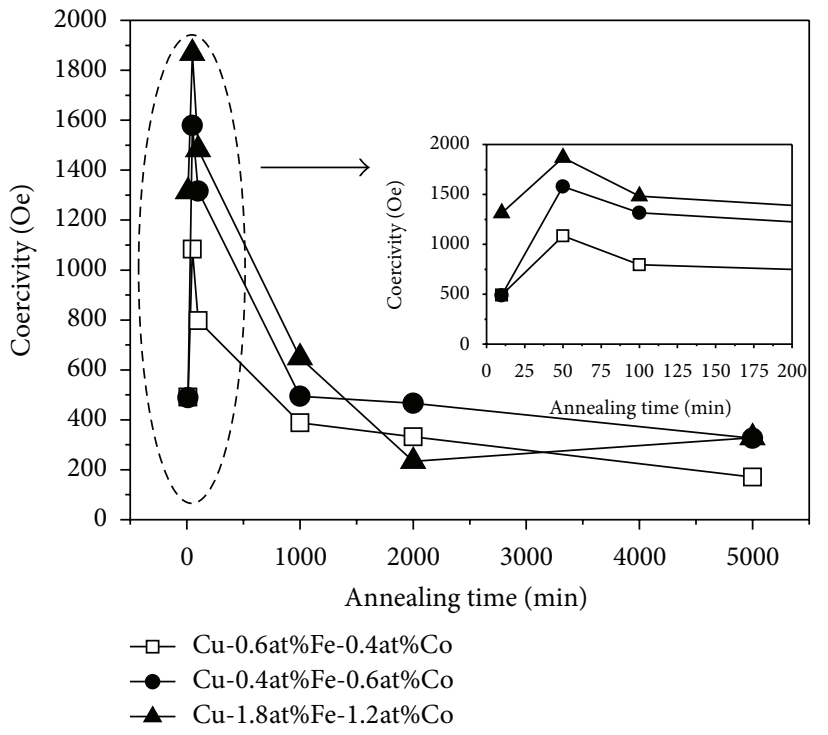

Figure 6: Temporal changes of coercivity in $\mathrm{Cu}-\mathrm{Fe}-\mathrm{Co}$ alloys annealed at $973 \mathrm{~K}$.

these results support the surmise described in 3.2. That is, the structural transition from a paramagnetic fcc-FeCo phase to ferromagnetic ordered B2 FeCo takes place at a particle size of $10-20 \mathrm{~nm}$. The deflection angle of Fe-Co particles is larger than that of pure iron particles. This trend is compatible with the previous works, because the saturation magnetization of B2 (bcc) Fe-Co phase is greater than that of pure iron [18]. 


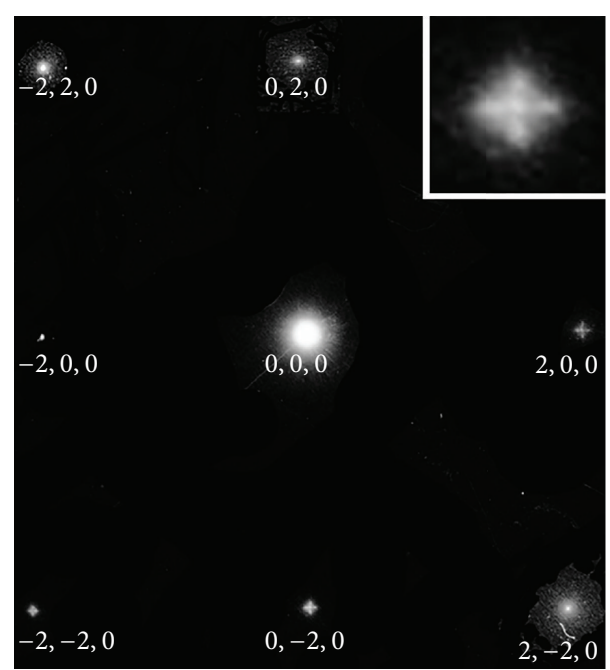

Figure 7: An example of low angle electron diffraction of $\mathrm{Cu}-$ 1.8 at $\%$ Fe-1.2at $\%$ Co.

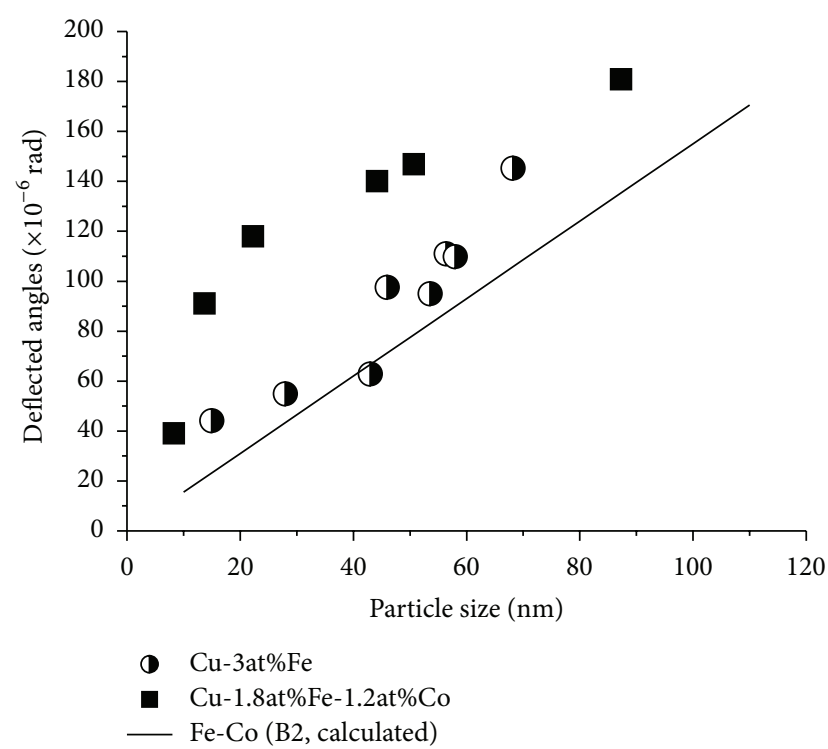

FIGURE 8: Deflected angles of parasitic reflection of $\mathrm{Cu}-1.8 \mathrm{at} \% \mathrm{Fe}-$ $1.2 \mathrm{at} \% \mathrm{Co}$ and $\mathrm{Cu}-3 \mathrm{at} \% \mathrm{Fe}$ alloys.

\section{Conclusions}

The present work has investigated the precipitation phenomena occurring in a $\mathrm{Cu}-\mathrm{Fe}-\mathrm{Co}$ alloy. Small solute particles initially formed as coherent fcc precipitates but rapidly transformed into B2 FeCo phase when the mean diameter of precipitates reached $10-20 \mathrm{~nm}$. At this condition of precipitation, twin-like structures were observed in the precipitates and SQUID measurements revealed that the coercivity exhibited a peak. Lorentz microscopy and SQUID measurements confirmed that the easy axis of magnetization of the ordered FeCo particles is $\langle 100\rangle$ and the magnitude of magnetization increased for the ternary $\mathrm{Cu}-\mathrm{Fe}-\mathrm{Co}$ alloys compared with binary $\mathrm{Cu}-\mathrm{Fe}$ alloys.

\section{Conflict of Interests}

The authors declare that there is no conflict of interests regarding the publication of this paper.

\section{Acknowledgments}

The authors wish to thank Professor Z. Hiroi of the University of Tokyo and Dr. M. L. Jenkins of the University of Oxford for critical readings and useful comments. This work was supported in part by Grants-in Aid for Scientific Research from JSPS of Japan (no. 18560643).

\section{References}

[1] P. Grünberg, R. Schreiber, Y. Pang, M. B. Brodsky, and H. Sowers, "Layered magnetic structures: evidence for antiferromagnetic coupling of Fe layers across Cr interlayers," Physical Review Letters, vol. 57, no. 19, pp. 2442-2445, 1986.

[2] M. N. Baibich, J. M. Broto, A. Fert et al., "Giant magnetoresistance of (001)Fe/(001)Cr magnetic superlattices," Physical Review Letters, vol. 61, no. 21, pp. 2472-2475, 1988.

[3] A. E. Berkowitz, J. R. Mitchell, M. J. Carey et al., "Giant magnetoresistance in heterogeneous $\mathrm{Cu}-\mathrm{Co}$ alloys," Physical Review Letters, vol. 68, no. 25, pp. 3745-3748, 1992.

[4] J. Q. Xiao, J. S. Jiang, and C. L. Chien, "Giant magnetoresistance in nonmultilayer magnetic systems," Physical Review Letters, vol. 68 , no. 25 , pp. 3749-3752, 1992.

[5] L. H. Chen, S. Jin, T. H. Tiefel, and R. Ramesh, "Creation of bulk, superlatticelike structure and giant magnetoresistance effect in a deformed $\mathrm{Cu}-\mathrm{Ni}-\mathrm{Fe}$ alloy," Applied Physics Letters, vol. 64, no. 8, pp. 1039-1041, 1994.

[6] J.-Q. Wang, P. Xiong, and G. Xiao, "Investigation of giant magnetoresistance in magnetic, concentrated, nanostructured alloys," Physical Review B, vol. 47, no. 13, pp. 8341-8344, 1993.

[7] M. Takeda, K. Inukai, N. Suzuki, G. Shinohara, and H. Hashimoto, "Precipitation behaviour of $\mathrm{Cu}-\mathrm{Co}$ alloys," Physica Status Solidi (A), vol. 158, no. 1, pp. 39-46, 1996.

[8] M. Takeda, N. Suzuki, G. Shinohara, T. Endo, and J. van Landuyt, "TEM study on precipitation behavior in $\mathrm{Cu}-\mathrm{Co}$ alloys," Physica Status Solidi (a), vol. 168, no. 1, pp. 27-35, 1998.

[9] M. Takeda, H. Yamada, S. Yoshida, K. Shimasue, T. Endo, and J. Van Landuyt, "TEM Study and Monte-Carlo simulation of nano-scale Co particles precipitated in a Cu matrix," Physica Status Solidi (A): Applied Research, vol. 198, no. 2, pp. 436-442, 2003.

[10] A. L. Rocha, I. G. Solórzano, and J. B. Vander Sande, "Heterogeneous and homogeneous nanoscale precipitation in dilute $\mathrm{Cu}$ Co alloys," Materials Science and Engineering: C, vol. 27, no. 5-8, pp. 1215-1221, 2007.

[11] T. Fujita, S. Nishimura, T. Fujinami, K. Kaneko, Z. Horita, and D. J. Smith, "Microstructure and magnetic properties of $\mathrm{Cu}$-Co alloys by severe plastic deformation," Microscopy and Microanalysis, vol. 11, supplement 82, pp. 1812-1813, 2005.

[12] J. R. Childress, C. L. Chien, and M. Nathan, "Granular Fe in a metallic matrix," Applied Physics Letters, vol. 56, no. 1, pp. 95-97, 1990.

[13] N. Wada, K. Takamatsu, M. Takeda, M. Takeguchi, and M. Blanchin, "The microstructure and magnetic properties of nano-scale Fe magnetic particles precipitated in a $\mathrm{Cu}-\mathrm{Fe}$ alloy," 
International Journal of Materials Research, vol. 101, no. 3, pp. 361-365, 2010.

[14] N. Wada, Y. Azuma, M. Takeda, and Z. Hiroi, “The relationship between the microstructure and the magnetic properties of nano-scale magnetic particles in a $\mathrm{Cu}-\mathrm{Fe}-\mathrm{Co}$ ternary alloy," International Journal of Materials Research, vol. 101, no. 3, pp. 356-360, 2010.

[15] S. Kang, T. Muramatsu, and M. Takeda, "TEM study and magnetic measurements of nano-scale particles formed in $\mathrm{Cu}-$ base alloys," Advanced Materials Research, vol. 89-91, pp. 757762, 2010.

[16] T. Shima and K. Takanashi, Handbook of Magnetism and Advanced Magnetic Materials, vol. 4 of edited by: H. Kronmuller, S. Parkin, Wiley, 2007.

[17] J. N. Chapman and M. R. Scheinfein, "Transmission electron microscopies of magnetic microstructures," Journal of Magnetism and Magnetic Materials, vol. 200, no. 1-3, pp. 729-740, 1999.

[18] D. I. Bardos, "Mean magnetic moments in bcc Fe-Co alloys," Journal of Applied Physics, vol. 40, no. 3, pp. 1371-1372, 1969. 

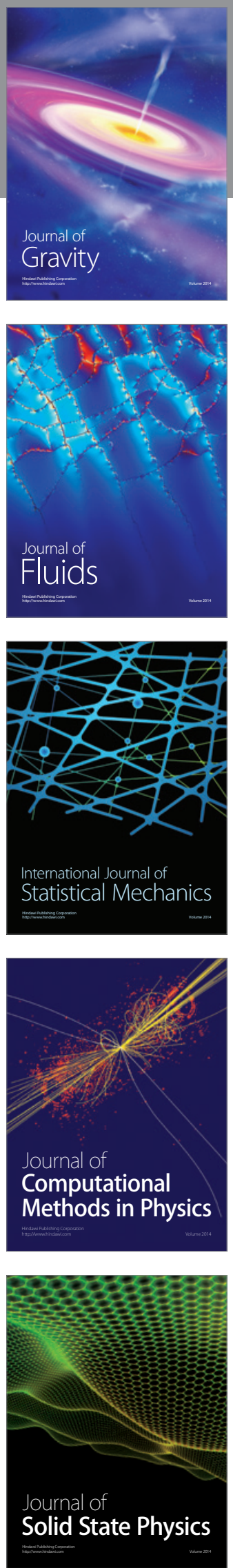

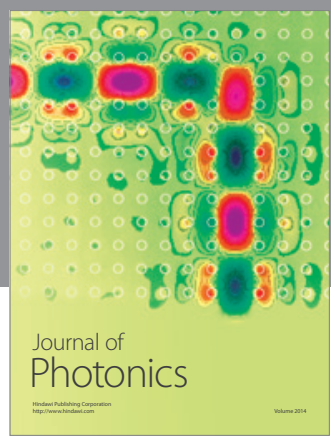

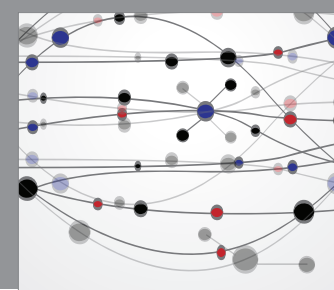

The Scientific World Journal

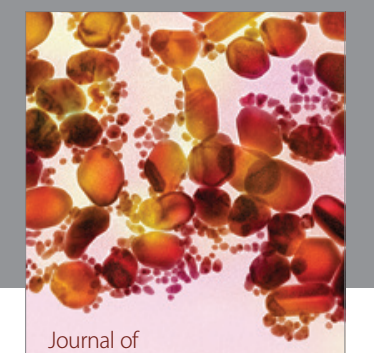

Soft Matter
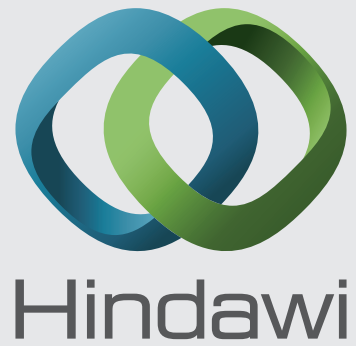

Submit your manuscripts at

http://www.hindawi.com
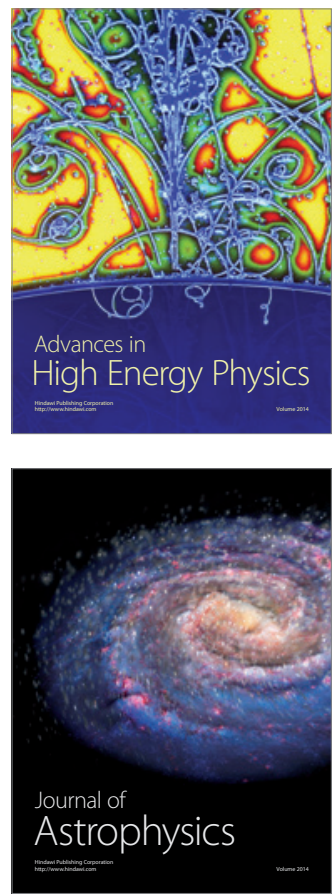
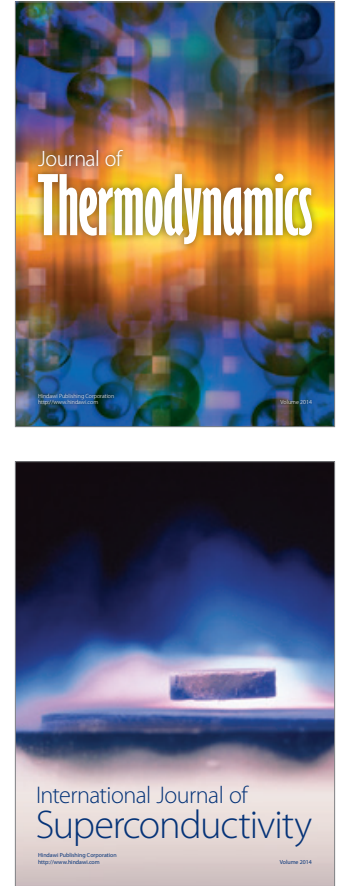
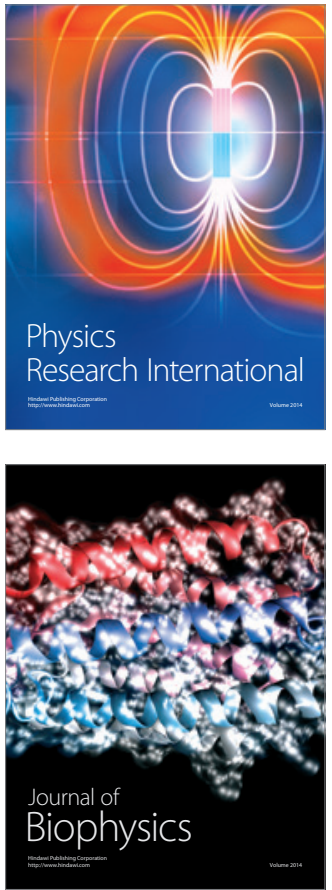
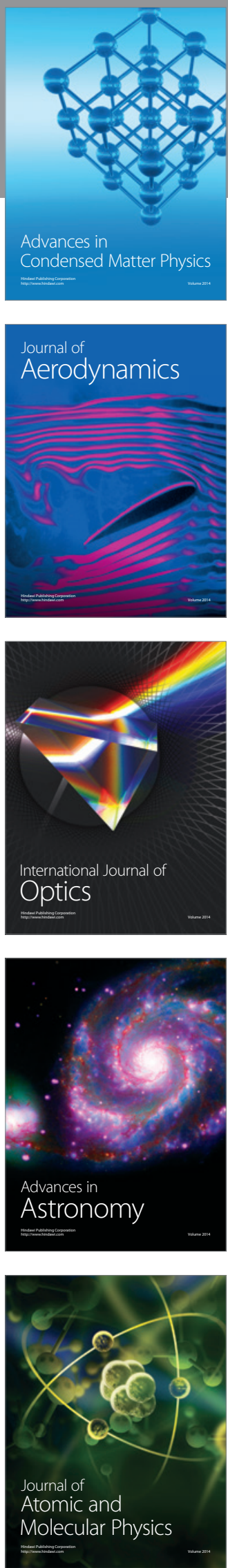